\title{
Etiology of Recurrence in Laparoscopic Inguinal Hernia Repair
}

\author{
Sarwal Ankush ${ }^{1 *}$ and Sharma Anil ${ }^{2}$ \\ Tata medical centre, Kolkata, India \\ Director, Institute of Minimal Access, Metabolic and Bariatric Surgery, Max Healthcare Institute Ltd., Saket, New Delhi, India \\ Received: March 15, 2019; Published: April 23, 2019 \\ *Corresponding author: Ankush Sarwal, Tata medical centre, Kolkata, India
}

\begin{abstract}
Various hernia guidelines have accepted laparoscopic hernia repair surgery as gold standard treatment for inguinal hernia patient. Laparoscopic procedures give the advantage of methodical dissection and exploration of the preperitoneal or extraperitoneal space with high resolution and magnified imaging technology. However, recurrence remains a clinical problem in present day scenario. Recurrences can occur at any stage after laparoscopic inguinal herniorrhaphy and carries substantial morbidity. The etiology to recurrence in hernias repair is multifactorial and includes both technical and non-technical aspects. All the measures to decrease the burden of recurrences should be used which can only be done by getting the knowledge of patient-related risk factors along with knowledge of the controllable technical risk factors. These may be classified into patient-related, surgeon-related and surgery/technique-related .Proper patient counselling about the modifiable factors such as weight, smoking should be given to patients to minimize the risk of recurrence. Surgeons' experience plays a vital role, but many factors other than surgical expertise and surgeon's competence operate in the causation of recurrences. We aim to review the risk factors responsible for these recurrences in laparoscopic mesh techniques.
\end{abstract}

Keywords: Laparoscopic Inguinal Hernia Repair, Inguinal Hernia, Recurrent Inguinal Hernia

\section{Introduction}

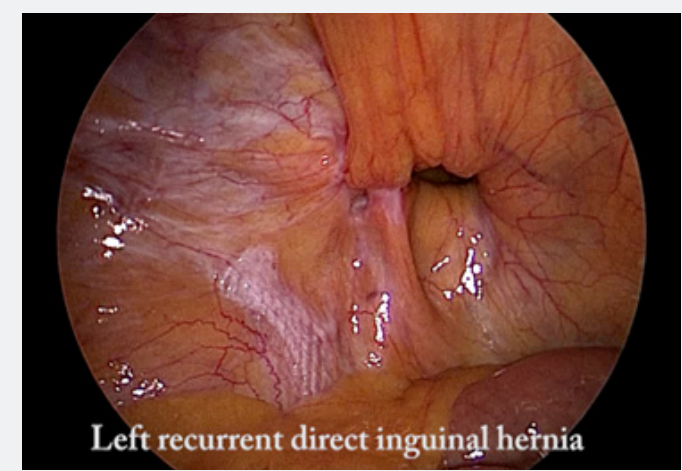

Figure 1: Showing left recurrent direct inguinal hernia with mesh seen displaced laterally.

Inguinal hernia repair is one of the most commonly performed general surgical operations, with more than 20 million patients undergo groin hernia repair annually worldwide. The incidence of recurrence is most often held as the measure of success used to compare the various methods of inguinal herniorrhaphy $[1,2]$. The incidence of recurrence after inguinal hernia repair is difficult to estimate accurately since it varies with duration of followup but may be as high as $15 \%$ has been reported in literature. Laparoscopic approaches i.e. transabdominal preperitoneal(TAPP) and totally extraperitoneal (TEP) have been increasingly utilized in recent days and with equal recurrence rates compared to its open counterpart $[3,4]$. Recurrence following laparoscopic inguinal herniorrhaphy can occur at any stage after the operation but tend to be more common in the first 3 years following the surgery [5] (Figure 1). Long-term Danish observational study, published in 2014, showed a reoperation rate after primary Lichtenstein repair to be $2.4 \%$, and after laparoscopic repair to be $3.3 \%$, which has been ranging from $1-4.3 \%$ for TAPP and from $0-3.5 \%$ for TEP $[6,7]$ The reason as to why inguinal hernias recur is most likely multifactorial.

\section{Etiological Factors}

A number of factors may contribute to the recurrence of an inguinal hernia. These may be classified into patient-related, surgeon-related and surgery/technique-related.

\section{Patient-related factors}

\section{General factors}

Gender: Females are more prone to inguinal hernia recurrence than males, high level of evidence is available to show that [8]. This has been based primarily on studies on open inguinal hernia repairs, suggesting that the increased rate of recurrence in female patients after open inguinal hernia repair 
is due to missed femoral hernias, which are missed routinely by surgeons during an open inguinal herniorrhaphy. But this finding has not been observed after laparoscopic inguinal herniorrhaphy. Laparoscopic repair of primary groin hernia in women had lower reoperation rates and fewer femoral recurrences than open repair techniques. This is due to the fact that ,the presence of femoral hernia (or for that matter any other groin hernia) is far easily detectable during a methodical dissection and exploration of the preperitoneal space which is routinely deployed for laparoscopic procedures [6,7].

Obesity: Obesity has shown a moderate level of link with increased recurrence. Poor wound healing and surgical site infection associated with obesity, other immunosuppressive factors (such as diabetes, smoking and steroid intake) lead to poor inflammatory response, which may contribute to increased recurrence from poor tissue integration of the mesh [8]. SchochIversen et al. found that a BMI of $\geq 30$ has a threefold higher risk of recurrence rate compared to those with a BMI of $<30$ [9].

Age: Increased age has not been consistently associated with increased recurrence [8].

Chronic cough(COPD) although has not been consistently demonstrated in literature but are often considered risk factors for recurrence [8].

Chronic constipation has not been consistently proven by studies, but this is believed to promote recurrence [8].

Family history: recurrence has not shown been shown to be affected by positive family history [8].

Chronic kidney disease, social class, Liver cirrhosis, work load, pregnancy, labour and race are incompletely studied factors, which may impact the risk of inguinal hernia recurrence [8]

\section{Local Factors}

Type of hernia: High level of evidence shows that direct hernias are more likely to recur. It is unclear whether this increased recurrence with direct hernias was because of insufficient mesh coverage beyond the pubic tubercle medially or it is purely an anatomical factor $[8,9]$.

Sliding Hernias: sliding hernias are associated with increased recurrence has moderate level of evidence [8].

Collagen Levels: Moderate level of evidence is available to suggest that diminished collagen type I/ III ratio is associated with increased recurrence [8]

Size of Hernia: it has been shown that size of hernia, $<3$ versus $\geq 3 \mathrm{~cm}$ does not appear affect the risk of recurrence [8].

\section{Surgeon-Related Factors}

Surgeons' experience plays a vital role in the outcome of any surgery and inguinal hernia is no exception. Less experienced and unsupervised trainees (i.e., <60 cases or 3 years' experience), performing open anterior mesh repair, studies have shown to have higher recurrence rates and longer operative times suggesting limited technical competency [10]. However, supervised and extensive experience training modifies this factor. Bracale et al. published a study comparing 100 TAPP procedures by two different trainees. The study showed that both trainees fully completed their learning curves for the TAPP after 65 procedures [11] Laparoscopic inguinal hernia repair is a technically advanced laparoscopic procedure with a steep learning curve [12-14]. The recurrence rate is seen to decline and stabilize over the first 100 cases; however, conversions, complications and operating time have been seen to improve even after 250 cases, which concludes that factors other than surgical expertise and surgeon's competence operate in the causation of recurrences [15].

\section{Surgical Technique \& Surgery-Related Factors}

\section{Surgical Technique Factors}

Following a standardized surgical steps protocol can contribute to lower recurrence rates. This is due to the fact that incorrect operative technique is one of the most important reasons for recurrence [9]. In open hernia surgeries, tension free mesh repair is associated with less recurrence rates, while sac invagination, without ligation in an indirect hernia, is associated with an increased incidence of recurrence [16]. In laparoscopic approach, an exposure of the entire my pectineal orifice is needed to ensure adequate overlap of the mesh on all potential hernia sites. If inadequate dissection is done, it may result in mismatch between the available inadequate space and mesh. This occurs due to intra-abdominal shearing forces causing the folded mesh to slide away from the defect or due to migration of a small mesh into the hernia defect by forces responsible for causing the hernia. On the other hand, a large mesh in a small space may balloon out through the defect giving the appearance of a recurrence [16]. Cord lipoma acts like a pseudo-recurrence . It is, therefore, recommended that these pre-peritoneal cord lipomas should be excised in the safest possible manner to prevent confusion in future exploration for a true recurrence of inguinal hernia $[17,18]$.

Polypropylene has been used traditionally in both open and laparoscopic inguinal herniorrhaphy. The initial Prolene meshes were heavy weight $(>80 \mathrm{~g} / \mathrm{m} 2)$ and micro porous $(<1 \mathrm{~mm})$ meshes, although lighter-weight polypropylene is available now days. The effect of weight differences alone on surgical outcomes is unknown with no clearly defined weight limit guidelines for LWMs and HWMs in present literature [19]. A single perfect mesh does not exist and, therefore, the choice of mesh remains an individual preference and its availability. All meshes are known to contract and shrink in size. Hence, selection of a mesh size that is too small or that provides inadequate overlap is associated with increased recurrence. So, a mesh not less than $10 \times 15 \mathrm{~cm}$ should be used in laparoscopic approach $[19,20]$. 
Recurrence may be associated with improper fixation technique. There are various techniques used to place and secure a mesh in the preperitoneal space which includes using absorbable and non-absorbable tacks, fibrin glue, tassel spray and sutures. Tissue-mesh interface is the weakest link in a prosthetic hernia repair. Poor grip of the weakened tissues or avulsion of the fixation device due to pressures and strain acting on the mesh could cause give-way of the mesh. The aim of mesh fixation in hernia repairs is to prevent early displacement, mesh migration and a consequent recurrence, although its mechanics are neither investigated in detail nor well understood [21]. In fixation by traumatic methods such as tacks or sutures, one needs to avoid blood vessels in the triangle of doom and nerves in the triangle of pain. Some surgeons feel that that the preperitoneal space is an enclosed space, which may not allow for significant migration of the mesh. Non-fixation of mesh using laparoscopic techniques has been proven to be safe and equally efficacious in various studies $[22,23]$. However, Traumatic mesh fixation is recommended in patients with large direct hernias (M3-EHS classification) undergoing TAPP or TEP to reduce recurrence risk [24].

\section{Surgery Related Factors}

Laparoscopic compared to open mesh repair was associated with lower incidence of wound infection ., Post-operative Surgical site infections (SSIs) have been shown in various studier to be associated with recurrence [5]. Postoperative hematoma and seroma formation may result in lifting of the mesh away from the tissues, which may lead to increased recurrence [25]. Emergency surgery may be a risk factor for hernia recurrence, but there is no conclusive data to support it [8]. There is no evidence in literature about any effect on recurrence with work and leisure activities, which can be resumed by most patients within three to five days following elective laparoscopic/open inguinal hernia repair [8].

\section{Conclusion}

With laparoscopic hernia repair surgery become one of the gold standard treatment for inguinal hernia patient ,recurrence after inguinal hernia repair remains a clinical problem in present day scenario Recurrences can occur at any stage after laparoscopic inguinal herniorrhaphy and carries substantial morbidity. The reason as to why hernias recur is most likely multifactorial and includes both technical and non-technical aspects. All the measures to decrease the burden of recurrences should be used which can only be done by getting the knowledge of patient-related risk factors along with knowledge of the controllable technical risk factors. Patients need to be counselled on some of the non-technical or modifiable risk factors such as higher BMI, smoking, diabetes, and use of steroids to minimize the risk of recurrence. Surgeons' experience plays a vital role, but many factors other than surgical expertise and surgeon's competence operate in the causation of recurrences.

\section{Authors Contributions}

All authors have contributed in study concept and design; data acquisition, drafting of the manuscript; critical revision of the manuscript for important intellectual content, material support and study supervision.

\section{References}

1. Jenkins JT, O’Dwyer PJ (2008) Inguinal hernias. Br Med J 336(7638): 269-272.

2. Kehlet H, Bay-Nielsen M, Danish Hernia Database C (2008) Nationwide quality improvement of groin hernia repair from the danish hernia database of 87,840 patients from 1998 to 2005 . Hernia 12: 1-7.

3. Schwab R, Willms A, Kroger A, Becker HP (2006) Less chronic pain following mesh fixation using a fibrin sealant in TEP inguinal hernia repair. Hernia 10: 272-277.

4. Lovisetto F, Zonta S, Rota E, Bottero L, Faillace G, et al. (2007) Laparoscopic transabdominal preperitoneal (TAPP) hernia repair: surgical phases and complications. Surg Endosc 21: 646-652.

5. El-Dhuwaib Y, Corless D, Emmett C, Deakin M, Slavin J (2013) Laparoscopic versus open repair of inguinal hernia: a longitudinal cohort study. Surg Endosc 27: 936-945.

6. Burcharth J, Andresen K, Pommergaard HC (2014) Recurrence patterns of direct and indirect inguinal hernias in a nationwide population in Denmark. Surgery 155: 173-177.

7. Burcharth J (2014) The epidemiology and risk factors for recurrence after inguinal hernia surgery. Dan Med J 61: B4846.

8. Jorgensen LN, Hope WW, Bisgaard T, Risk Factors for the Development of Inguinal Hernias in Adults. Chapter 2. Hernia Surge Guidelines Part 1.

9. Schjøth-Iversen L, Refsum A, Brudvik KW (2017) Factors associated with hernia recurrence after laparoscopic total extraperitoneal repair for inguinal hernia: a 2-year prospective cohort study. Hernia 21: 729735 .

10. Bingener J, Simmermacher R, Lomanto D, Training and the Learning Curve. Chapter 22. HerniaSurge Guidelines Part 3.

11. Bracale U, Merola G, Sciuto A, Cavallaro G, Andreuccetti J, Pignata G (2018) Achieving the learning curve in laparoscopic inguinal hernia repair by Tapp: a quality improvement study. J Invest Surg June 14:1-8.

12. Bansal VK, Krishna A, Misra MC (2016) Learning Curve in Laparoscopic Inguinal Hernia Repair: Experience at a Tertiary Care Centre. Indian J Surg 78: 197-202.

13. Lim JW, Lee JY, Lee SE (2012) The learning curve for laparoscopic totally extraperitoneal herniorrhaphy by moving average. J Korean Surg Soc 83: 92-96.

14. Choi YY, Kim Z, Hur KY (2012) Learning curve for laparoscopic totally extraperitoneal repair of inguinal hernia. Can J Surg 55: 33-36.

15. Schouten N, Simmermacher RK, van Dalen T (2013) Is there an end of the "learning curve" of endoscopic totally extraperitoneal (TEP) hernia repair? Surg Endosc 27: 789-794.

16. Lowham AS, Filipi CJ, Fitzgibbons RJ (1997) Mechanisms of hernia recurrence after preperitoneal mesh repair: traditional and laparoscopic. Ann Surg 225: 422e31.

17. Felix E, Scott S, Crafton B (1998) Causes of recurrence after laparoscopic hernioplasty. A multicenter study. Surg Endosc 12: 226-231.

18. Niebuhr HKF (2017) Surgical risk factors for recurrence in inguinal hernia repair-a review of the literature. Innov Surg Sci 2: 53-59. 
19. Weyhe D, Klinge U Meshes. Chapter 10. HerniaSurge Guidelines Part 1.

20. Messaris E, Nicastri G, Dudrick SJ (2010) Total extraperitoneal laparoscopic inguinal hernia repair without mesh fixation: prospective study with 1-year follow-up results. Arch Surg 145: 334-338.

21. Arvidsson D, Smedberg S (2000) Laparoscopic compared with open hernia surgery: complications, recurrences and current trends. Eur J Surg 166 (Suppl 585): 40-47.

22. Garg P, Rajagopal M, Varghese V, Ismail M (2009) Laparoscopic total extraperitoneal inguinal hernia repair with nonfixation of the mesh for 1,692 hernias. Surg Endosc 23:1241-1245.

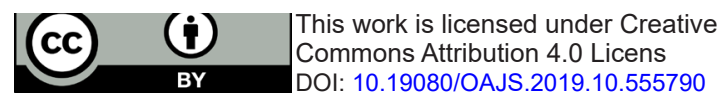

23. Teng YJ, Pan SM, Liu YL, Yang KH, Zhang YC, et al. (2011) A meta-analysis of randomized controlled trials of fixation versus nonfixation of mesh in laparoscopic total extraperitoneal inguinal hernia repair. Surg Endosc 25: 2849-2858.

24. Fortelny RH, Sanders DL, Montgomery A, Mesh fixation. Chapter 11. Hernia Surge Guidelines Part 1.

25. Olmi S, Scaini A, Erba L, Guaglio M, Croce E (2007) Quantification of pain in laparoscopic transabdominal preperitoneal (TAPP) inguinal hernioplasty identifies marked differences between prosthesis fixation systems. Surgery 142: 40-46.

\section{Your next submission with Juniper Publishers will reach you the below assets}

- Quality Editorial service

- Swift Peer Review

- Reprints availability

- E-prints Service

- Manuscript Podcast for convenient understanding

- Global attainment for your research

- Manuscript accessibility in different formats

( Pdf, E-pub, Full Text, Audio)

- Unceasing customer service

Track the below URL for one-step submission https://juniperpublishers.com/online-submission.php 